\title{
APPLICATION OF GAS-CHROMATOGRAPHY MASS SPECTROMETRY TO RESEARCH AND ROUTINE TESTING
}

\author{
J. M. JOUANY, Ph.D.(Pharm. \& Tox.), Y. BONNAIRE, M.Pharm., \\ J. BELEGAUD, Ph.D.(Pharm. \& Tox.) and C. BOUDENE, Ph.D.(Pharm. \& Tox.) \\ Laboratoire d'Analyses des Société de Courses Parisiennes et Laboratoire de Toxicologie, \\ Faculté des Sciences Pharmaceutiques et Biologiques de I'Université Paris-Sud, \\ Rue J. B. Clément, 92290 Chatenay-Malabry, France
}

\begin{abstract}
Mass spectrometry, employing the Finnigan 3200 apparatus is used in conjunction with gas chromatography for both routine testing and research investigations. Its use in the former is confined to saliva samples when not accompanied by urine from the same horse, to urine samples in which suspicious compounds are not identifiable by conventional procedures, for confirmation of drugs in saliva when the accompanying urine result is positive, and for screening for compounds difficult to detect by other means.
\end{abstract}

Extraction of drugs from biological fluids is by solvent or XAD-2 resin and screening of residues makes use of GC, UV absorptiometry and thin-layer chromatography. The rationale of the screening procedure is presented in Fig. 1.

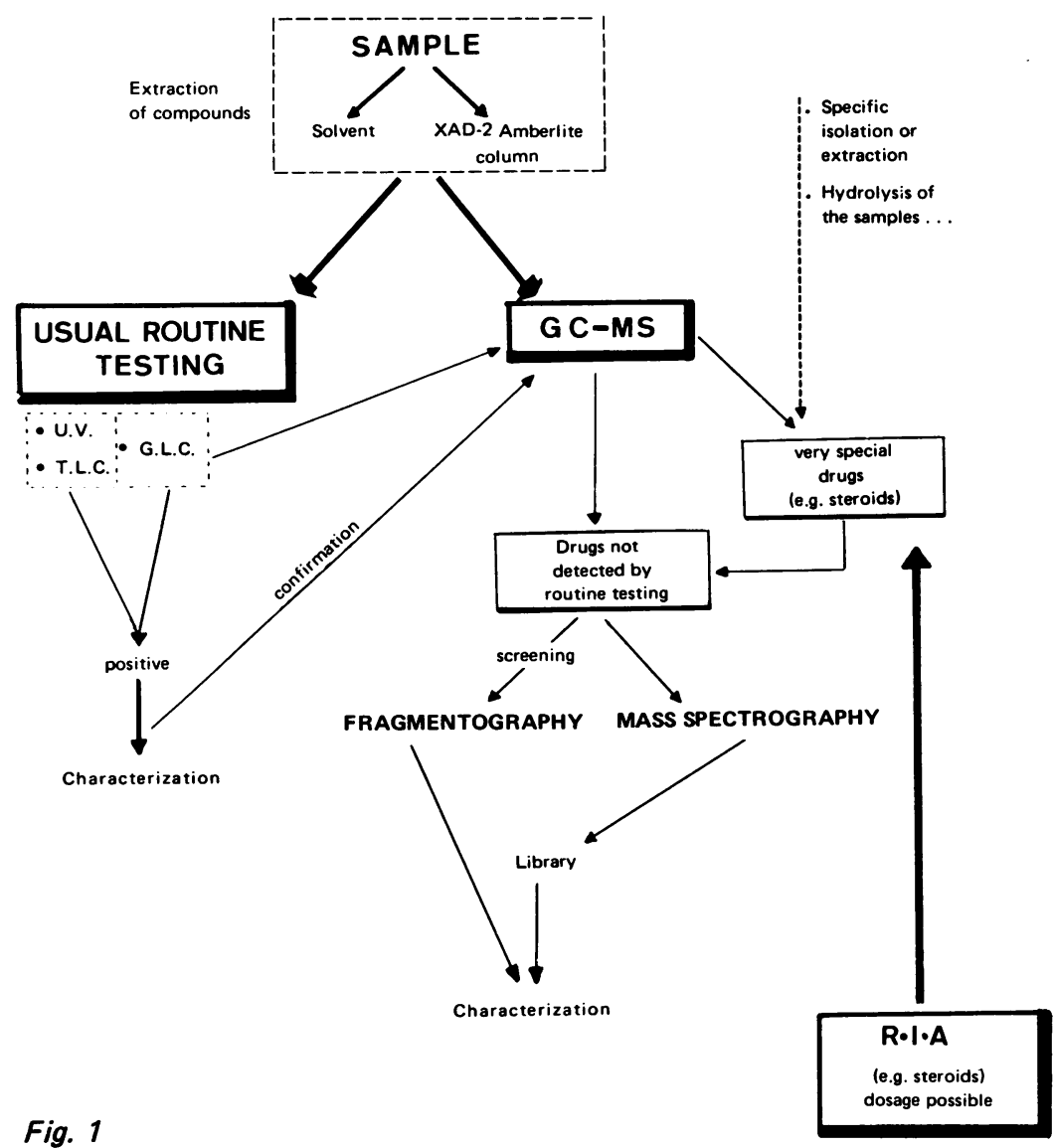

